\title{
Counter-Extremism, PREVENT and the Extreme Right Wing: Lessons Learned and Future Challenges
}

\author{
Authors: Dr Chris Allen ${ }^{1}$, Dr Arshad Isakjee ${ }^{2} \&$ Mrs Özlem Ögtem-Young ${ }^{3}$
}

Keywords: extremism, right wing, policy

\section{Introduction}

In recent years, the extreme right wing (XRW) has undergone significant and rapid change to the extent that it now presents a very real threat to the domestic security of the United Kingdom (UK). This has resulted in a number of challenges for various stateex, institutional and grassroots stakeholders including how to appropriately and effectively respond and counter this growing threat. Among these challenges are concerns as to whether existing counter-tremism policies and measures - to date having almost solely been applied in response to Islamist extremism - remain fit for purpose. This Working Paper draws on interdisciplinary research into governmental, institutional and community responses to Islamist extremism in the city of Birmingham to speak directly to these concerns. Informed and contextualised by our findings, we provide an overview of counter-extremism policy, consider the criticisms and concerns expressed about these, set out the evidence base for the growing threat posed by the XRW, before highlighting a number of challenges stakeholders will need to consider if they are to avoid the errors of the past and build on the lessons learned. As well as making a new and timely contribution, we hope this paper will stimulate and provoke further discussion about the changing nature of the UK's domestic extremism threat and the policy measures in place.

\section{Methods}

In this paper, we draw on the findings from collaborative research undertaken over the past halfdecade. Working across and within the disciplines of criminology, geography, social policy and sociology, our research focused on better understanding counter-extremism policies in relation to Islamist extremism as well as the social, political and cultural impacts these had. We engaged with more than 200 stakeholders in the city, including local authority counter-extremism leads and

\footnotetext{
${ }^{1}$ Associate Professor, Centre for Hate Studies, Department of Criminology, University of Leicester

${ }^{2}$ Lecturer, Geography \& Planning, University of Liverpool

${ }^{3}$ Research Associate, Department of Social Policy, Sociology \& Criminology, University of Birmingham
} 


\section{WORKING PAPER 3}

teams, the police, counter-terrorism units, local councillors, community activists, third sector workers and the general public. As well as traditional research methods including interviews, focus groups and scholarly and non-specialist literature reviews, a number of more innovative approaches were used including participant and naturalistic observation, workshops, policy analysis and walked interviews.

\section{Counter-Extremism Policy in Context}

Since 9/11, Islamist-inspired terror attacks across the world have catalysed governments - the UK included - to implement various policy approaches to counter the threat posed by terrorism and the extremist ideologies seen to underpin them. A marked feature of these policies has been the need to 'prevent' individuals from becoming terrorists or supporting those who do. Allowing the state, its actors and institutions to intervene in the 'pre-criminal space', these policies have been contentious and criticised as potentially counter to the conventions of the criminal justice system. In the UK, a further layer of criticism has been evident. Whilst the government has said that its counter-extremism policies have been necessary to prevent all forms of extremism, critics claim that the emphasis on Islamist extremism has resulted in those with Muslim identities being disproportionately targeted (Allen, 2017b).

PREVENT is the UK's counter-extremism strategy; one of the four strands of CONTEST, the wider counter-terrorism strategy. Introduced following the $7 / 7$ attacks in 2005, PREVENT sought to: respond to the ideological challenge of terrorism and the threat from those who promote it; prevent people from being drawn into terrorism while ensuring they are given appropriate advice and support; and work with sectors and institutions where there are risks of radicalisation, for instance health, education and criminal justice (Home Office, 2011). Integral to this was CHANNEL, a de-radicalisation programme supporting those early identified as being vulnerable to terrorism (HM Government, 2015).

The PREVENT programme has undergone a substantive shift in policy since the pathfinder schemes began in 2008. What began as a community-based plan to intervene in communities, by for example, promoting 'better' governance for mosques and targeting young people thought to be at risk of social harm, has now transformed into a policy that is institutionalised within existing government service structures. PREVENT is now active in universities, schools, and within the health service to spot and manage 'risk' (Ragazzi 2016). In both guises, the PREVENT programme has struggled to evidence effectiveness, and indeed presented its own risks in relation to the stigmatisation of Muslim communities. While $£ 80 \mathrm{~m}$ was invested in PREVENT in its first six years (Casciani, 2014), little or no evaluation was undertaken, and it is unclear as to the extent to 


\section{WORKING PAPER 3}

which specific programmes reduce 'risk'. This resulted in a palpable loss of confidence and trust in PREVENT. From criminological and sociological disciplinary perspectives, a number of studies emerged which suggested that PREVENT: constructed Muslims as 'suspect communities' (Pantazis \& Pemberton, 2009; Hickman, Thomas, Silvestri \& Nickels, 2011); functioned as a stateendorsed mechanism to spy on Muslims (Kundnani, 2014); and reinforced suspicions about Muslims that had the potential to justify Islamophobia (Alam \& Husband, 2013).

The expansion of PREVENT in conjunction with over-zealous and egregious examples of failed counter-terrorism policies has fed into broader sentiments of mistrust between government authorities and Muslims. For example, Project Champion, a city-specific initiative that saw more than 200 CCTV cameras being installed around two of the city's most densely populated Muslim areas was shown by our research to have lasting implications for community trust of police and counter-terrorism officials (Isakjee and Allen 2013). While neither funded nor managed via PREVENT, it reinforced many of the criticisms and concerns already in circulation about the strategy. In terms of identity, those engaged felt that their communities were being constructed as enemy 'Others'. There was a profound anger and discomfort about the appearance of counterterrorism technology used by security and military services abroad being turned inward to streets and neighbourhoods here. The long and difficult process of diaspora communities feeling at home in the UK was effectively set in reverse. Latterly, our research found that due to counter-extremism policies, some young Muslims self-censored their normal behaviours for fear that, akin to their identities and lived places, these too would be misconstrued as extraordinary, insidious and even dangerous (Ögtem-Young, 2017). Clearly, counter-extremism policies can have very real detrimental impacts.

\section{Evidencing the Extreme Right Wing Threat}

Criminological analysis evidences the growing threat posed by the XRW. In addition to four XRW terror plots having been foiled since March 2017 (Grierson, 2018), other examples include the murder of Jo Cox - Member of Parliament (MP) for Batley and Spen - by Thomas Mair in 2016; proscription of the ultra-nationalist National Action the same year (Allen, 2017a); the terror vanramming incident at the Finsbury Park Mosque in 2017 and the 2018 conviction of Jack Renshaw for plotting to kill the MP Rosie Cooper and Detective Constable Victoria Henderson. To add to this, Max Hill QC - the UK's former independent reviewer of terror legislation - recently warned the government not to underestimate the XRW.

New policy-related data from the Home Office further adds to this evidence-base. To the year ending March 2018, PREVENT received 1,312 XRW referrals. This number accounted for 18\% 


\section{WORKING PAPER 3}

of all referrals. While Islamist referrals continue to outnumber those from the XRW, the number of XRW referrals has increased $36 \%$ in the past year. The previous year, the number of XRW referrals increased by 25\%. Home Office data also shows that the past year was the first time similar numbers of Islamist and XRW PREVENT referrals received support from CHANNEL: 179 Islamist referrals and $174 \mathrm{XRW}$. The significance of this is that, as a percentage, disproportionately more XRW referrals (41\%) than Islamist (27\%) received CHANNEL support. Criminal justice system statistics can also be used to evidence the threat posed by the XRW. This can be seen in the fact that the majority of arrests (38\%) in relation to terrorism offences now relate to the XRW (Dearden, 2018). Similarly, the number of XRW extremists in custody has risen from 10 to 28 in the past year. As Max Hill put it, the growing threat posed by the XRW should not be underestimated.

\section{Rethinking Counter-Extremism Measures for the XRW}

The evidenced response to the XRW to date is both welcome and commendable. In addition, it affords an opportunity to revisit and rethink PREVENT and wider counter-extremism approaches. Far from providing conclusive evidence that PREVENT has not historically targeted Muslims, the evidenced response to the XRW via PREVENT does suggest that contemporarily, PREVENT is far from exclusive. It remains to be seen however whether this will refute other criticisms of PREVENT: constructing Muslims as 'suspect communities' and reinforcing Islamophobic suspicions among the general public. Nonetheless, it can be categorically posited that PREVENT has undergone some evidenced change which has the potential to confer some legitimacy on historical governmental rhetoric.

While positive, lessons learned from our interdisciplinary research inform a number of potential challenges identified regarding the delivery of PREVENT in relation to the XRW. The first relates to the embedded notion of 'communities' in the delivery of PREVENT. For Isakjee (2014), while references to 'communities' seem credible and authentic when referring to ethnic and religious minorities, they are far less so when applied to majority ('white') communities. Accordingly, the notion of 'communities' has limits. In this respect, as Islamist extremism was responded to via Muslim 'communities' to what extent do analogous 'communities' exist as regards the XRW? Anecdotally, the XRW is usually identified with 'white working class communities'. While so, this is crude and simplistic - also problematic - as 'Muslim communities' has been in the past. In this way, PREVENT could be seen to unduly target 'white working class communities' in the same way it did Muslims previously. To avoid duplicating criticisms and concerns, some rethinking might be appropriate. 


\section{WORKING PAPER 3}

Similarly with the language and descriptors used. If the notion of 'communities' continues to be necessarily embedded in the design and delivery of PREVENT, some rethinking might be required as to how those same 'communities' might be referred to and named. The potentially problematic nature of this was evident at a recent counter-extremism workshop, where one stakeholder referred to those vulnerable to the XRW as "poorly educated, ill informed". Aside from being as insulting as it was demeaning, employing such language could not only alienate and denigrate a considerable swathe of people, it could also be seen to construct enemy 'communities' in the same way some would suggest 'Muslims' has in the past. Given that our research highlighted the potential detrimental impacts in relation to identity, place and belonging, it is imperative that similar mistakes are not made again as regards responding to the XRW.

Further thinking might also be necessary to ensure consistency and equity when delivering counterextremism measures. Noting that domestic extremism is far from homogenous, and thereby necessitating a portfolio of appropriate measures, what is problematic are the clear inconsistencies that already exist within these measures. Take for example, how groups and movements are categorised. Engagement work with stakeholders shows that groups and movements are categorised as XRW when they have a propensity to use or justify violence. Because of this, street protest groups such as the English Defence League and Britain First - neither of which openly advocate violence - are categorised as 'far-right'. National Action and Blood \& Honour however - both of whom do advocate violence - are categorised as XRW. While there is merit in this, that same categorisation is far from consistent as regards Islamist groups and movements. Consequently, rarely are groups such as Hizb ut-Tahrir and al-Muhajiroun categorised differently to each other, despite only the latter openly justifying violence. Any lack of consistency and equity therefore has the capacity to be interpreted as treating Islamist and XRW extremism - and by extension, 'Muslim' and 'white' communities - differently. In doing so, another opportunity to challenge and refute historical criticisms of PREVENT would be lost to the extent that they could even be reinforced.

Similar too when regarding known sites of extremist activity. In the past, known spaces where Islamist extremists have been active (for example gyms and cafes) have been targeted by local authorities and police in order to shut them down. Anecdotal knowledge about XRW sites (for example public houses and labour clubs) suggests a greater reluctance on the part of local authorities and police to do the same. From engaging stakeholders, this is because of the fear that shutting down a local public house would likely attract unwanted attention and even become a cause célèbre for other far-right and XRW actors. While acknowledging the potential for this, more 


\section{WORKING PAPER 3}

thinking might be required about how best to explain why different approaches and measures might be necessary.

\section{Conclusion}

As has been the case for the past few years, the XRW is likely to pose a threat to the domestic security of the UK for the foreseeable future. With the XRW having undergone significant change - as also has the socio-political landscape of the UK - this has and likely will continue to present state, institutional and community stakeholders with a variety of new challenges. However, this is an area that remains under-researched. In this respect, more research is required given the growth of the XRW and the threat it can be seen to be posing. While our research in Birmingham largely focused on Islamist extremism, the response to this and the impact it had on communities, through doing so from an interdisciplinary perspective enabled us to not only consider a wider range of ideas and issues but so too to put forward a greater breadth of findings. Not only has this enabled us to further engage various PREVENT and counter-extremism stakeholders in the city and beyond, as regards Islamist extremism, but so too has it enabled us - as set out here - to use these findings to advance thinking about XRW extremism, highlight some potential pitfalls and put forward some concerns as regards ensuring PREVENT and other counter-measures are implemented effectively, consistently and equitably. Cutting across policy, identity, place and belonging among others, our interdisciplinary research has the potential to contribute more solutions to problems than if the research had been undertaken from a single discipline or area of practice. This Working Paper is part of this process, seeking to prompt further thinking and research. Similarly, this Working Paper will be disseminated to PREVENT, counter-extremism and other appropriate stakeholders as a means of continuing engagement and dialogue. 


\section{References}

\section{WORKING PAPER 3}

Alam, Y., \& Husband, C. (2013). Islamophobia, community cohesion and counter-terrorism policies in Britain. Patterns of Prejudice, 47(3), 235-252.

Allen, C. (2017a). Proscribing National Action: Considering the Impact of Banning the British FarRight Group. The Political Quarterly, 88(4), 652-659.

Allen, C. (2017b). Stop, Question, and Frisk: A Response via the UK's Prevent Programme. Criminology, Criminal Justice, Law \& Society, 18(3), 65-69.

Casciani, D. (2014). Analysis: The Prevent strategy and its problems. BBC News, 26 August 2014 https://www.bbc.co.uk/news/uk-28939555 (accessed 1 October 2018)

Dearden, L. (2018). Number of white people arrested for terror offences outstrip any other single ethnic group, new figures show. Independent, 13 September 2018 https://www.independent.co.uk/news/uk/crime/terror-arrests-white-people-number-homeoffice-ethic-group-asian-a8535551.html (accessed 20 September 2018).

Grierson, J. (2018) White people make up largest proportion of British terror arrests. Guardian, 13 September 2018 https://www.theguardian.com/uk-news/2018/sep/13/white-people-make-uplargest-proportion-of-terror-arrests-figures-show (accessed 20 September 2018).

Halliday, J., \& Dodd, V. (2015). UK anti-radicalisation Prevent strategy a 'toxic brand. Guardian, 9 March 2015 https://www.theguardian.com/uk-news/2015/mar/09/anti-radicalisation-preventstrategy-a-toxic-brand (accessed 6 October 2018).

HM Government (2011). Revised Prevent Duty Guidance: for England and Wales. London: HM Government.

HM Government (2015). Channel Duty Guidance: Protecting vulnerable people from being drawn into terrorism. London: HM Government.

Home Office (2018) Individuals referred to and supported through the Prevent Programme, April 2017 to March 2018: Statistical bulletin 31/18. London: Home Office.

Isakjee, A. (2014). Why there is no such thing as the Muslim 'community'. The Conversation, 6 November 2014 https://theconversation.com/why-there-is-no-such-thing-as-the-muslimcommunity-33862 (accessed 21 September 2018). 


\section{WORKING PAPER 3}

Isakjee, A., \& Allen, C. (2013). 'A catastrophic lack of inquisitiveness': A critical study of the impact and narrative of the Project Champion surveillance project in Birmingham. Ethnicities, 13(6), 751770.

Kundnani, A. (2014). The Muslims are coming! Islamophobia, extremism and the domestic war on terror. London, UK: Verso.

Ögtem-Young, Ö. (2017) Youth perspectives on violent extremism, belonging and identity in Birmingham. Birmingham: University of Birmingham.

Pantazis, C., \& Pemberton, 5. (2009). From the 'old to the 'new suspect community: Examining the impacts of recent UK counter-terrorist legislation. British Journal of Criminology, 49(5), 646-666.

Ragazzi, F. (2016). Suspect community or suspect category? The impact of counter-terrorism as 'policed multiculturalism'. Journal of Ethnic and Migration Studies, 42(5), 724-741. 